\title{
Anti-biofilm Activities from Resveratrol against Fusobacterium nucleatum
}

\author{
Zhiyan He, Zhengwei Huang, Wei Zhou, Zisheng Tang, Rui Ma and Jingping Liang*
}

Department of Endodontics, Shanghai Research Institute of Stomatology, Ninth People's Hospital, Shanghai Jiao Tong University School of Medicine, Shanghai Key Laboratory of Stomatology, Shanghai, China

Fusobacterium nucleatum is a Gram-negative, anaerobic bacterium that plays an important role in dental plaque biofilm formation. In this study, we evaluate the effect of resveratrol, a phytoalexin compound, on F. nucleatum biofilm formation. The effects of different concentrations of resveratrol on biofilms formed on 96-well microtiter plates at different time points were determined by the MTT assay. The structures and thicknesses of the biofilm were observed by confocal laser scanning microscopy (CLSM), and gene expression was investigated by real-time PCR. The results showed that resveratrol at sub-MIC levels can significantly decrease biofilm formation, whereas it does not affect the bacterial growth rate. It was observed by CLSM images that the biofilm was visually decreased with increasing concentrations of resveratrol. Gene expression was down regulated in the biofilm in the presence of resveratrol. Our results revealed that resveratrol

OPEN ACCESS

Edited by: Bart Devreese, Ghent University, Belgium

Reviewed by:

J. Christopher Fenno, University of Michigan, USA

Ulvi Kahraman Gürsoy, University of Turku, Finland

${ }^{*}$ Correspondence: Jingping Liang liangjpdentist@126.com

Specialty section: This article was submitted to Antimicrobials, Resistance and Chemotherapy,

a section of the journal Frontiers in Microbiology

Received: 02 February 2016 Accepted: 24 June 2016 Published: 05 July 2016

Citation:

He Z, Huang Z, Zhou W, Tang Z, Ma $R$ and Liang J (2016) Anti-biofilm Activities from Resveratrol against

Fusobacterium nucleatum.

Front. Microbiol. 7:1065.

doi: 10.3389/fmicb.2016.01065 can effectively inhibit biofilm formation.

Keywords: F. nucleatum, resveratrol, biofilm, gene expression, antimicrobials

\section{INTRODUCTION}

In natural and industrial environments, bacteria mostly grow as biofilms attached to surfaces or are associated with interfaces, where bacterial cells are encased in a self-produced extracellular polymeric matrix. Biofilm formation is a complex and multifactorial process that involves at least two steps. The first step involves the adherence of the bacterial cells to the host surface; subsequently, adherent cells form a multilayer biofilm covered by an extracellular matrix (Flemming and Wingender, 2010; Trappetti et al., 2011; Srinandan et al., 2015). The microorganisms in the biofilm undergo profound changes during the shift from a planktonic lifestyle. After incorporation into the biofilm, microorganisms are resistant not only to host defense mechanisms, such as phagocytosis, but also to antimicrobial agents. This change has been suggested to be involved in the persistence of infection by such microorganisms (Costerton et al., 1999; Jacqueline and Caillon, 2014).

Dental plaque biofilms are composed of a very complex mixture of species of bacteria, and their formation is highly ordered, starting with the initial colonizing bacteria attaching to the tooth surface with the acquired pellicle and subsequent coaggregation of late colonizers. More than 700 bacterial species have been detected in the human oral cavity. Among them, Fusobacterium nucleatum is frequently isolated from both supra- and sub-gingival dental plaque biofilms in humans. F. nucleatum is a Gram-negative, anaerobic, non-motile, non-spore-forming, spindleshaped, or fusiform rod bacterium. It plays an important role in the development of complex dental plaque biofilms as a bridge bacterium interaction with early and late colonizing bacteria in the oral cavity (Kolenbrander et al., 2006; Sasaki-Imamura et al., 2010; Tian et al., 2010; Ali Mohammed et al., 2013). 
The worldwide practice of indiscriminate and continuous use of antibiotics for the control and prophylaxis of bacterial pathogens has led to the development of bacterial resistance to most available antimicrobials. Antibiotics used as antibiotic growth promoters by adding continuously to animal feeds in very low amounts also play a significant role in the emergence of resistant bacteria. The rising number of infections caused by bacterial isolates resistant to conventional antibiotics has led to an intense search for novel antimicrobials and chemotherapeutics, including natural chemicals and natural plant products, which have generated increased interest with regard to their potential for use in treating infectious diseases (van den Bogaard and Stobberingh, 2000; Molhoek et al., 2011; de Lima Pimenta et al., 2013). Resveratrol (trans- 3,5,4'-trihydroxystilbene) is a naturally derived polyphenol natural product that is mainly found in the skin of grapes, berries, and so on and is also a component of red wine. Resveratrol has a broad range of biological effects, which include antimicrobial, antioxidant, antiinflammatory, antiaging, anticarcinogenic, and neuroprotective effects (Augustine et al., 2014; Lee K. et al., 2014). As a natural product, resveratrol may be an effective biofilm inhibitor. Recent studies have indicated that resveratrol inhibits the biofilm formation of some bacterial pathogens, including Vibrio cholerae, Staphylococcus aureus, Escherichia coli O157:H7, and Pseudomonas aeruginosa (Augustine et al., 2014; Lee J.H. et al., 2014; Qin et al., 2014).

There has been increasing interest in natural products as agents for preventing oral diseases, particularly dental biofilm-related diseases (Sintim and Gursoy, 2016). Millhouse et al. (2014) have already studied the effect of resveratrol on multi-species biofilm containing Streptococcus mitis, F. nucleatum, Porphyromonas gingivalis, and Aggregatibacter actinomycetemcomitans. Their results showed that resveratrol did not appear to have bactericidal properties against multi-species biofilms (Millhouse et al., 2014).

Therefore, in this study, we investigated the effect of resveratrol on biofilm formation by $F$. nucleatum. We mainly focused on the effects of resveratrol on the aggregation of bacteria, different stages of biofilm formation, biofilm structure and gene expression. To our knowledge, this is the first report describing the effect of resveratrol on F. nucleatum aggregation, biofilm formation and structure. This research would offer the possibility of the use of natural product resveratrol to prevent F. nucleatum biofilm infections. It may useful in the development of natural product as novel antimicrobial agents to treat and prevent of dental diseases.

\section{MATERIALS AND METHODS}

\section{Bacterial Strains and Growth Conditions}

The F. nucleatum ATCC10953 strain was provided by the State Key Laboratory of Oral diseases, West China Hospital of Stomatology, Sichuan University. Planktonic and biofilm forms of the F. nucleatum ATCC10953 strain were grown in Brain Heart Infusion Broth (BHI; Difco Laboratories, Sparks, MD, USA) at $37^{\circ} \mathrm{C}$ under anaerobic conditions $\left(80 \% \mathrm{~N}_{2}, 10 \% \mathrm{CO}_{2}\right.$, and $10 \%$ $\mathrm{H}_{2}$ ).

\section{Effects of Resveratrol on Planktonic Cell Growth}

The F. nucleatum ATCC10953 strain was used to anaerobically inoculate a fresh $\mathrm{BHI}$ culture with different concentrations of resveratrol $\left(0,12.5,25,50,100 \mu \mathrm{g} \mathrm{ml}^{-1}\right)$ at $37^{\circ} \mathrm{C}$ without agitation. The optical density at $600 \mathrm{~nm}$ was measured using a spectrophotometer (UV1601, Shimadzu, Japan) at different time intervals. The experiment was replicated three times with triplicate samples at each time point.

\section{Effects of Resveratrol on Biofilm Formation}

To quantify F. nucleatum biofilm growth, we applied the MTT [3-(4,5-dimethylthiazol-2-yl)-2,5-diphenyl tetrazolium bromide] assay in 96-well polystyrene plates (He et al., 2012). An overnight culture at a final concentration of $10^{6} \mathrm{CFU} / \mathrm{ml}$ was added to $200 \mu \mathrm{l}$ of fresh BHI liquid medium in each flat-bottom well with different concentrations of resveratrol $(0,1.5625,3.125,6.25$, $12.5,25 \mathrm{\mu g} \mathrm{ml}^{-1}$ ). The plates were then incubated at $37^{\circ} \mathrm{C}$ for different times $(24,36,48 \mathrm{~h})$ without agitation. The culture was then removed, and the wells carefully washed three times with sterile phosphate-buffered saline (PBS) to remove non-adherent cells. The cultures were stained with $100 \mu \mathrm{l}$ of MTT $\left(5 \mathrm{mg} \mathrm{ml}^{-1}\right)$ for $3 \mathrm{~h}$ in a dark place and washed three times with PBS. Next, $100 \mu$ l of lysing solution [10\% (v/v) sodium dodecyl sulfate and $50 \%(\mathrm{v} / \mathrm{v})$ dimethylformamide in distilled water] was added to dissolve the biofilm for $3 \mathrm{~h}$ at room temperature before reading the $\mathrm{OD}_{590} \mathrm{~nm}$ values. All of the experiments were performed in triplicate with at least three replicates, and wells without cells were used as blank controls.

\section{Aggregation Assays}

Aggregation experiments were performed as previously described with minor modifications (He et al., 2015). Briefly, F. nucleatum was grown overnight in $\mathrm{BHI}$ broth with different concentration of resveratrol $\left(0,1.5625,3.125,6.25,12.5,25 \mu \mathrm{g} \mathrm{ml}^{-1}\right)$. The bacteria were harvested by centrifugation at $13,400 \mathrm{~g}$ for $30 \mathrm{~s}$, washed twice with PBS, and resuspended in PBS to an optical density of approximately 0.6 at $600 \mathrm{~nm}$, as determined by using a spectrophotometer. All of the samples were incubated at $37^{\circ} \mathrm{C}$ for $150 \mathrm{~min}$, and the $\mathrm{OD}_{600} \mathrm{~nm}$ was recorded at different time intervals $(0,20,40,60,90,120$, and $150 \mathrm{~min})$. Before measurement, the samples were equilibrated at room temperature for $5 \mathrm{~min}$. The percentage of aggregation was calculated as follows: $\left(\mathrm{OD}_{600 \mathrm{~nm}}\right.$ at time zero - $\mathrm{OD}_{600 \mathrm{~nm}}$ at time $\mathrm{x} \mathrm{min}) /\left(\mathrm{OD}_{600 \mathrm{~nm}}\right.$ at time zero $) \times 100 \%$. All of the experiments were performed in triplicate.

\section{Effects of Resveratrol on the Biofilm Structure}

Fusobacterium nucleatum biofilms were formed on glass-bottom chamber slides with different concentrations of resveratrol $(0$, $1.5625,3.125,6.25,12.5,25 \mu \mathrm{g} \mathrm{ml}^{-1}$ ) for $24 \mathrm{~h}$ at $37^{\circ} \mathrm{C}$. The biofilms formed on each sheet were washed twice with saline to remove unbound cells and stained for $30 \mathrm{~min}$ in the dark with L7012 LIVE/DEAD BacLight TM bacterial cells containing SYTO 
9 dye and propidium iodide (Molecular Probes, Inc., Eugene, OR, USA). A confocal laser scanning microscope (CLSM; Leica TCS SP2, Leica microsystems, Germany) was used to record confocal image stacks in five random locations near the center of each slide. Five confocal data sets were recorded at $40 \times$ magnification with a numerical aperture of 1.25 and Leica confocal software was analyzed for the thicknesses of the biofilms and bacterial vitality, and the average and standard deviation were calculated. In each experiment, the exciting laser intensity, background level, contrast, and electronic zoom were maintained at the same level.

\section{RNA Extraction, Reverse Transcription, and $\mathrm{qPCR}$}

The biofilms that formed with different concentrations of resveratrol $\left(0,12.5,25 \mu \mathrm{g} \mathrm{m} \mathrm{m}^{-1}\right)$ at $24 \mathrm{~h}$ were harvested by centrifugation, resuspended in Trizol reagent (Takara) and transferred to an RNase-free $1.5 \mathrm{ml}$ microcentrifuge tube. Total RNA extractions were performed according to the manufacturer's instructions. Purified RNA was dissolved in $20 \mu \mathrm{l}$ of DEPCtreated water and stored at $-80^{\circ} \mathrm{C}$ until required for cDNA labeling. A cDNA synthesis kit (Takara) was used to generate cDNA. The reverse transcription reaction mixture $(20 \mu \mathrm{l})$ containing $4 \mu \mathrm{l}$ of $5 \times$ buffer (containing dNTP and $\mathrm{Mg}^{2+}$ ), $1 \mu \mathrm{l}$ of PrimeScript RT Enzyme Mix I, $1 \mu$ l of Oligo dT primer, $1 \mu$ l of random hexamers, and $1 \mu \mathrm{g}$ of an RNA sample, was incubated at $37^{\circ} \mathrm{C}$ for $15 \mathrm{~min}$ and the reaction was terminated at $85^{\circ} \mathrm{C}$ for $5 \mathrm{~s}$ according to the manufacturer's instructions. The cDNA samples were stored at $-20^{\circ} \mathrm{C}$ until use.

The qPCR reaction mixture $(20 \mu \mathrm{l})$ contained $1 \times$ SYBR Green PCR master mix, $5 \mu \mathrm{l}$ of template cDNA, and $0.5 \mu \mathrm{M}$ of the appropriate forward and reverse PCR primers. qPCR conditions included an initial denaturation at $98^{\circ} \mathrm{C}$ for $5 \mathrm{~min}$, followed by a 40 -cycle amplification consisting of denaturation at $98^{\circ} \mathrm{C}$ for $15 \mathrm{~s}$, annealing at $50^{\circ} \mathrm{C}$ for $15 \mathrm{~s}$, and extension at $72^{\circ} \mathrm{C}$ for $30 \mathrm{~s}$. The resulting $\mathrm{cDNA}$ and negative control were amplified using an Applied Biosystems 7900HT Fast Real Time PCR System (Applied Biosystems). The expression levels of all of the tested genes (Table 1) as determined by qPCR were normalized using

TABLE 1 | Nucleotide sequences of primers used in this study.

\begin{tabular}{lll}
\hline Primer & Primer sequence $\left.\mathbf{( 5}^{\prime} \mathbf{- 3} \mathbf{3}^{\prime}\right)$ & Target \\
\hline Fn 16S F & AAGCGCGTCTAGGTGGTTATGT & 16S rRNA \\
Fn 16S R & TGTAGTTCCGCTTACCTCTCCAG & 16S rRNA \\
Fn 0116 RT-F & GTATCCCTGCTGCTCCAA & FN0116 \\
Fn 0116 RT-R & GTGCTTCTGCTTCCTTAGTC & FN0116 \\
Fn 0132 RT-F & CCAATGCCACTGATGAACCT & FN0132 \\
Fn 0132 RT-R & CAGCAGCTGAGACAGCATTG & FN0132 \\
Fn 0503 RT-F & TCACCCTTGAGATTCCTTT & FN0503 \\
Fn 0503 RT-R & GAAGTTGCAAAGGCTAAAAGC & FN0503 \\
Fn 0659 RT-F & GTTGGAGCAACACCAGTTCC & FN0659 \\
Fn 0659 RT-R & CCAAGTGGTTCAACATGCAC & FN0659 \\
Fn 0675 RT-F & ATTGACCCAGCAAAAGTAC & FN0675 \\
Fn 0675 RT-R & GGCATCATTCCACCAGCA & FN0675 \\
Fn 1856 RT-F & TCTGCTGCTGTTGTTGCTT & FN1856 \\
Fn 1856 RT-R & GGGTGGAGCAATGGACTTAG & FN1856
\end{tabular}

the 16S rRNA gene of F. nucleatum as an internal standard (Lee et al., 2011). Each assay was performed with three independent RNA samples in triplicate. The fold changes of the expression levels were using the $\Delta \Delta C_{\mathrm{q}}$ method.

\section{Statistical Analysis}

Analysis of variance (ANOVA) with post hoc test was used to calculate the significance of the difference between the biofilms formed by $F$. nucleatum with or without resveratrol under the tested conditions (SPSS 15.0 software, USA). $P<0.05$ was considered statistically significant.

\section{RESULTS}

\section{Effects of Resveratrol on Planktonic Cell Growth}

The growth of $F$. nucleatum with different concentrations of resveratrol over a time course showed the bacteriostatic effect of resveratrol. It was observed that in comparison to the control, the bacterial growth was significantly inhibited with $50 \mu \mathrm{g} \mathrm{ml}^{-1}$ resveratrol treatment (Figure 1). The MIC for F. nucleatum using resveratrol was recorded as $100 \mu \mathrm{g} \mathrm{ml}^{-1}$. However, there was no obvious difference in the growth curve with resveratrol concentrations below $25 \mu \mathrm{g} \mathrm{ml}^{-1}$.

\section{Effects of Resveratrol on the Biofilms}

The effect of resveratrol on biofilm formation was evaluated when F. nucleatum was grown in 96-well plates of polystyrene. SubMIC levels of resveratrol $\left(0-25 \mu \mathrm{g} \mathrm{ml}^{-1}\right)$ were supplemented in the media from the onset of incubation with F. nucleatum (Figure 2). After $24 \mathrm{~h}$, F. nucleatum exhibited OD $590 \mathrm{~nm}$ values of $0.474 \pm 0.028$. With increasing concentrations of resveratrol, the biofilms formed by F. nucleatum exhibited $\mathrm{OD}_{590 \mathrm{~nm}}$ values that decreased from $0.347 \pm 0.038$ at $1.5625 \mu \mathrm{g} \mathrm{ml}^{-1}$ to $0.136 \pm 0.018$ at $25 \mu \mathrm{g} \mathrm{ml}^{-1}$ after a $24 \mathrm{~h}$ incubation. Similar trends were

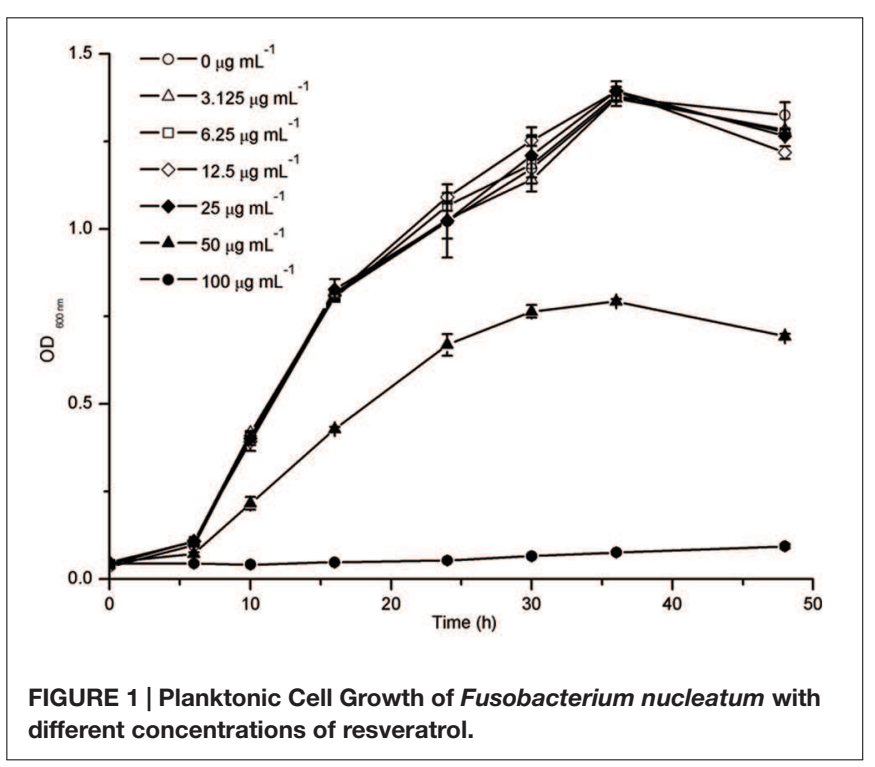




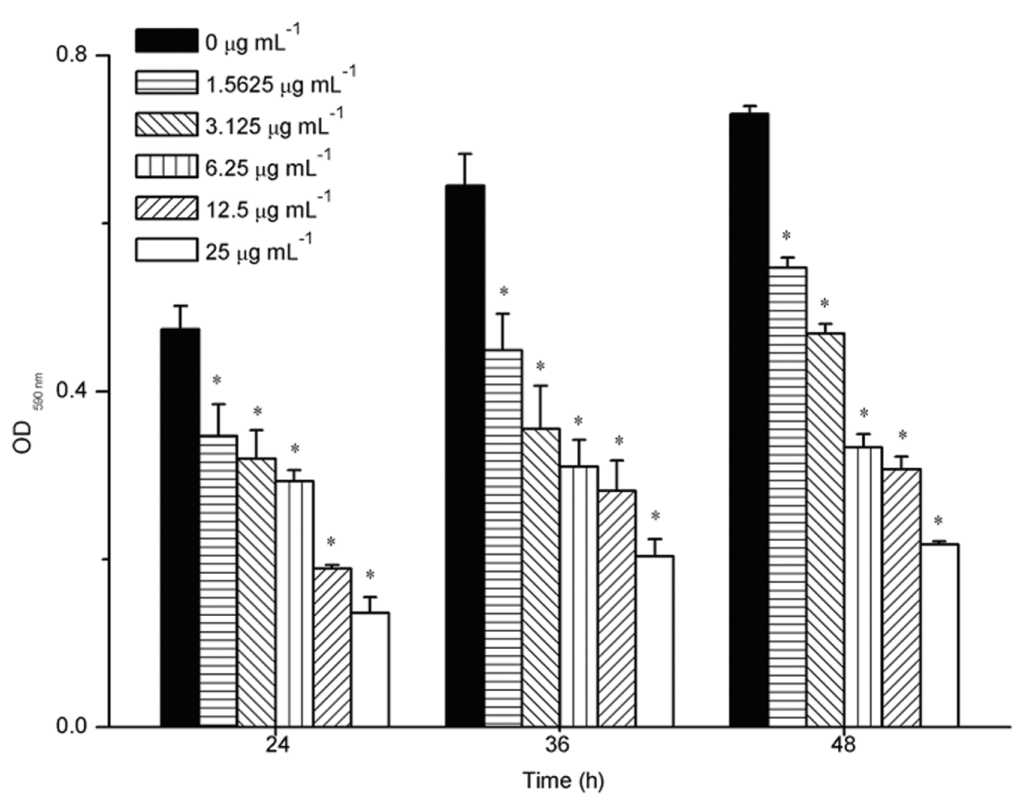

FIGURE 2 | Biofilm formation of $\boldsymbol{F}$. nucleatum with different concentrations of resveratrol at different time points. Statistically significant differences $\left({ }^{*} P<0.05\right)$ between with or without resveratrol at different time points.

observed after 36 and $48 \mathrm{~h}$. The biofilms formed by F. nucleatum exhibited OD $590 \mathrm{~nm}$ values of $0.645 \pm 0.038$ and $0.730 \pm 0.010$ at 36 and $48 \mathrm{~h}$, respectively, whereas in the presence of resveratrol, the values decreased from $0.449 \pm 0.043$ at $1.5625 \mu \mathrm{g} \mathrm{ml}^{-1}$ to $0.203 \pm 0.020$ at $25 \mu \mathrm{g} \mathrm{ml}^{-1}$ after a $36 \mathrm{~h}$ incubation and decreased from $0.548 \pm 0.012$ at $1.5625 \mu \mathrm{g} \mathrm{ml}^{-1}$ to $0.217 \pm 0.005$ at $25 \mathrm{\mu g}^{-} \mathrm{ml}^{-1}$ after a $48 \mathrm{~h}$ incubation, respectively. It was shown that resveratrol could effectively inhibit biofilm formation at different time points.

\section{Effects of Resveratrol on Aggregation}

The aggregation of F. nucleatum is shown in Figure 3. In general, the extents of aggregation increased with the increasing time, but the extents of aggregation mildly increased after $90 \mathrm{~min}$. As shown in Figure 3, the extents of aggregation of F. nucleatum without resveratrol reached $21.75 \%$ after $150 \mathrm{~min}$. The extents of aggregation with 1.5625 and $3.125 \mu \mathrm{g} \mathrm{ml}^{-1}$ resveratrol was slightly increased compared to bacteria grown without resveratrol. However, the extents of aggregation noticeably increased when the concentration of resveratrol reached $6.25 \mu \mathrm{g} \mathrm{ml}^{-1}$. F. nucleatum quickly aggregated with $25 \mu \mathrm{g} \mathrm{ml}^{-1}$ resveratrol, and cell aggregation was apparent by visual inspection. The maximum extents of aggregation for F. nucleatum reached $59.31 \%$ with $25 \mu \mathrm{g} \mathrm{ml}^{-1}$ resveratrol after $150 \mathrm{~min}$.

\section{Effects of Resveratrol on the Biofilm Structure}

The surface area of glass-bottom chamber slides that were covered with a $F$. nucleatum biofilm was characterized using CLSM after $24 \mathrm{~h}$ of incubation (Figure 4). In the absence of

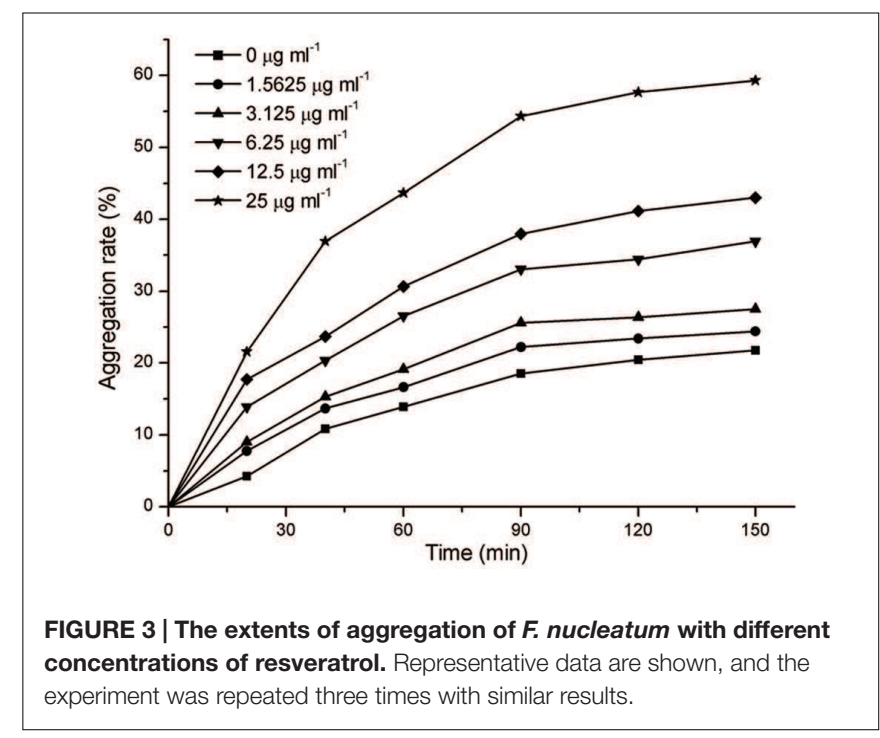

resveratrol, the biofilm formed by $F$. nucleatum had a uniform distribution with complete coverage of the attached surface. The biofilm appeared loose and tended to gather into relatively small aggregates that were easily discernible in accordance with resveratrol added to the culture. The biofilm thickness after $24 \mathrm{~h}$ of cultivation without resveratrol was observed to be up to $46.171 \pm 3.369 \mu \mathrm{m}$. The biofilm thickness became thinner with increasing concentrations of resveratrol, and it was only approximately $16.811 \pm 1.626 \mu \mathrm{m}$ at a $25 \mu \mathrm{g} \mathrm{ml}^{-1}$ concentration of resveratrol $(P<0.05)$. We also calculated that the proportion of viable (green) cells among all cells was $84.15 \pm 1.69 \%$, $82.19 \pm 3.88 \%, 84.53 \pm 1.56 \%, 85.48 \pm 1.77 \%, 85.25 \pm 2.47 \%$, 
A
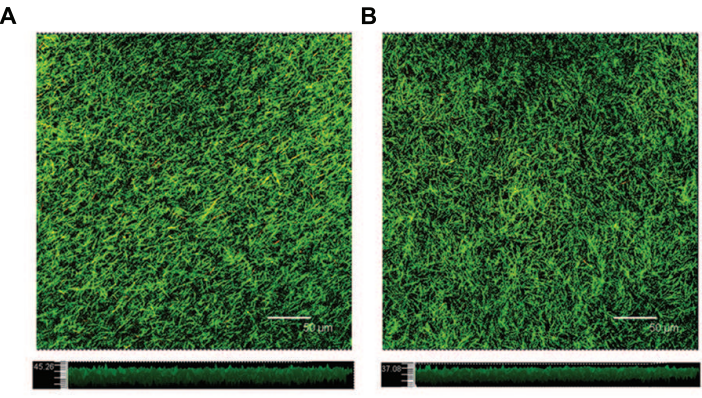

C

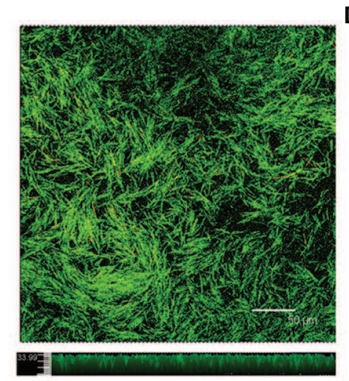

E
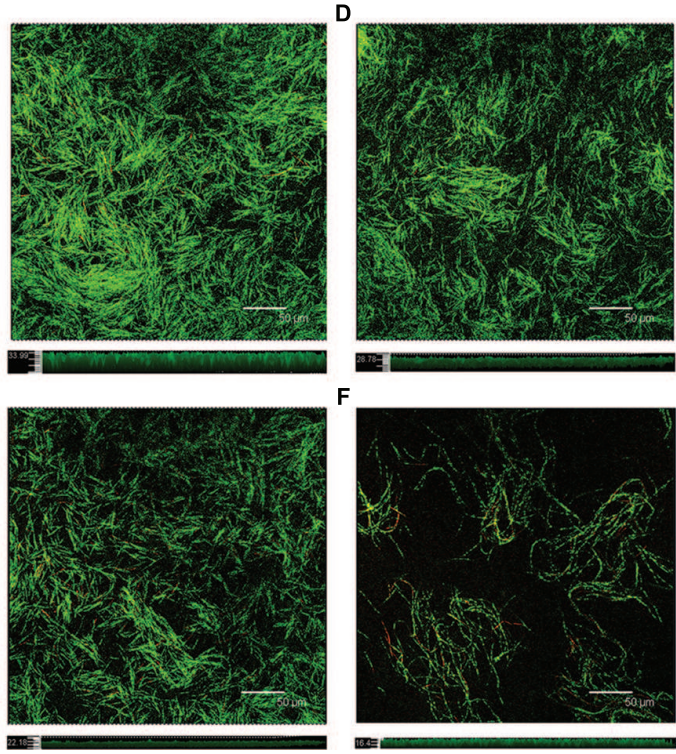

$F$

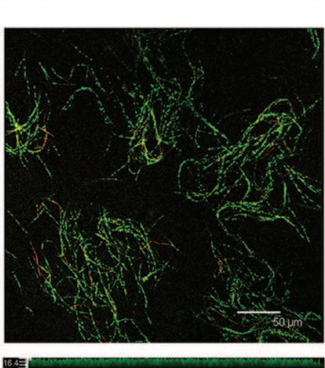

FIGURE 4 | Confocal laser scanning micrographs of the biofilm formed with different concentrations of resveratrol. Top sections represent the $\mathrm{X}-\mathrm{Y}$ panels, and bottom sections represent the Z-scales, respectively.

(A) $0 \mu \mathrm{g} \mathrm{ml}^{-1}$; (B) $1.5625 \mu \mathrm{g} \mathrm{ml}^{-1}$; (C) $3.125 \mathrm{~g} \mathrm{ml}^{-1}$; (D) $6.25 \mu \mathrm{g} \mathrm{ml}^{-1}$; (E) $12.5 \mu \mathrm{g} \mathrm{ml}^{-1}$; (F) $25 \mu \mathrm{g} \mathrm{ml}^{-1}$. Bar $=50 \mu \mathrm{m}$.

$84.71 \pm 2.85 \%$ with different resveratrol treatment $(0,1.5625$, $3.125,6.25,12.5,25 \mu \mathrm{g} \mathrm{ml}^{-1}$ ), respectively.

\section{Gene Expression in the Biofilms}

To gain insight into gene expression, real-time PCR analysis was used to quantify the effect of 12.5 and $25 \mu \mathrm{g} \mathrm{ml}^{-1}$ resveratrol on the biofilms formed by $F$. nucleatum. The selected genes including FN0116 and FN0675 encoding stress-induced proteins, FN0132 encoding hemolysin, FN0503 encoding LysRfamily transcriptional regulator, FN0659 encoding the ABC transporter substrate binding protein and FN1856 encoding butyrate-acetoacetate CoA-transferase subunit were considered to be important virurence factors (Skar et al., 2003; Lee et al., 2011). In general, six tested genes (Table 1) were down-regulated in the biofilms grown with resveratrol compared to cells grown without resveratrol (Figure 5). Additionally, the relative fold changes of the levels of the gene transcripts decreased with increasing resveratrol concentration. Transcription of FN0132 in the biofilms formed by $F$. nucleatum were significantly downregulated after 12.5 and $25 \mu \mathrm{g} \mathrm{ml}^{-1}$ resveratrol treatment, with the relative change being 0.12 - and 0.02 -fold, respectively. The expression of other down-regulated genes in the biofilms with resveratrol, including FN0116, FN0503, FN0659, FN0675 and FN1856, were reduced, ranging from approximately 0.46to 0.21 -fold at $12.5 \mu \mathrm{g} \mathrm{ml}^{-1}$ and from approximately 0.28 - to 0.08 -fold at $25 \mu \mathrm{g} \mathrm{ml}^{-1}$. We also compared the gene expression of planktonic cultures and the result showed that there was no obvious difference in gene expression between planktonic cultures by $F$. nucleatum with or without resveratrol $(P>0.05)$ (Supplementary Figure S1).

\section{DISCUSSION}

Fusobacterium nucleatum is commonly cultivated from the subgingival plaque of periodontitis patients, and because of its ability to congregate with many oral bacteria, it functions as a bridge between early and late colonizers in the dental plaque biofilm (Ali Mohammed et al., 2013). Biofilm formation regulates F. nucleatum survival and invasiveness including surviving in an aerobic environment, invading the epithelium. F. nucleatum also decrease in membrane permeability to resist antimicrobial stress (Gursoy et al., 2010; Keskin et al., 2014).

At the start of this study, we investigated the effect of resveratrol on bacterial growth. Our results demonstrated that resveratrol did not significantly affect the growth rate of the bacteria at concentrations up to $50 \mu \mathrm{g} \mathrm{ml}^{-1}$. Thus, we studied whether resveratrol can affect biofilm formation at sub-MIC concentrations through MTT assays. This assay is to convert the yellow tetrazolium salt MTT to intracellular insoluble purple formazan by metabolically active cells. The MTT assay has been used to detect the effect of antibiofilm agents in the biofilm formation in many previous studies (Chusri et al., 2012; He et al., 2012; de Lima Pimenta et al., 2013). Therefore, we used this assay for the quantification of viable biofilm bacteria and the result was shown that resveratrol attenuated the biofilm formation more effectively when the concentration increased, ranging from 1.5625 to $25 \mu \mathrm{g} \mathrm{ml}^{-1}$. No significant planktonic cell growth rate inhibition was detected at concentrations that inhibited biofilm formation. Our results suggested that the mechanisms by which resveratrol exerts its effects on F. nucleatum biofilms at sub-MICs were distinctly different from the mode of action of resveratrol for growth inhibition. According to the CLSM images, the thickness of biofilms after $24 \mathrm{~h}$ of cultivation was thinner with increasing concentrations of resveratrol. We also found that the proportion of viable (green) cells among all cells following resveratrol treatment was similar to the proportion without treatment, as determined through CLSM by staining with SYTO9/PI (a DNA-binding dye that stains both living and dead cells). Therefore, unlike antibiotics that are used to inhibit cell growth, resveratrol may be identified as a biofilm inhibitor that does not affect bacterial growth.

The ability of bacterial cells to come into contact and form aggregates, or autoaggregation is considered important for colonization of host cells in pathogenic bacteria (Lee et al., 2010; Abdel-Nour et al., 2014). During biofilm development, autoaggregation is a process through which a strain within 


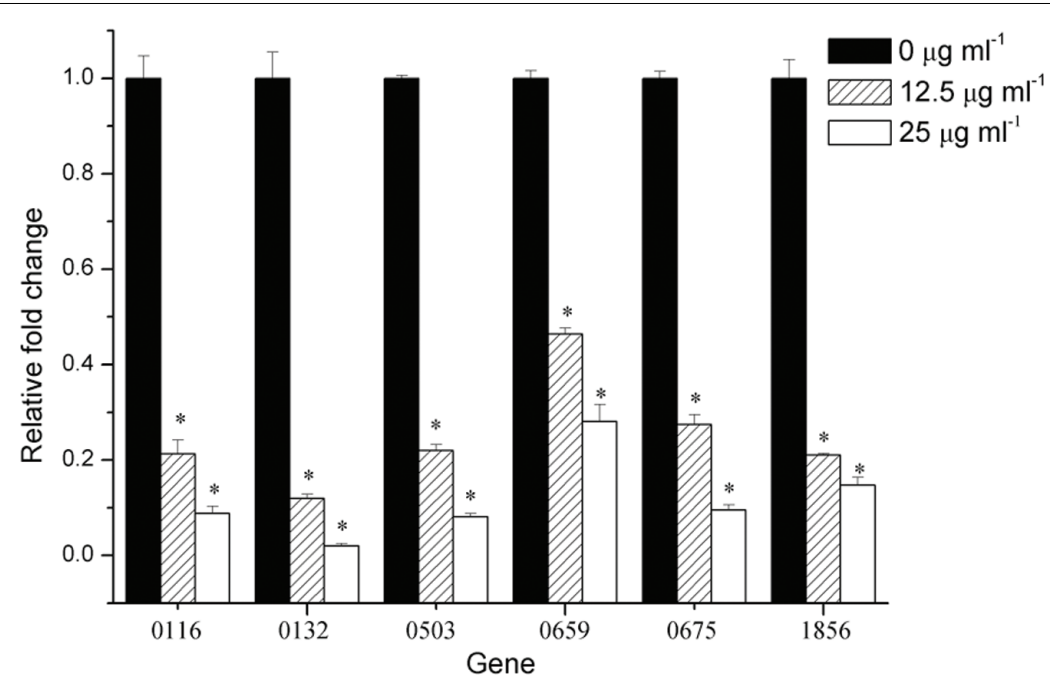

FIGURE 5 | Gene expression of $\boldsymbol{F}$. nucleatum strain biofilms. The results represent the means and SDs of at least three independent experiments performed in triplicate. Statistically significant differences $\left({ }^{*} P<0.05\right)$ in gene expression between different concentrations.

the biofilm produces polymers to boost the integration of genetically identical strains, and is also a prerequisite of biofilm formation (Zhang et al., 2004; Das et al., 2010; Nyenje et al., 2012). However, the results of the present study showed that resveratrol increased $F$. nucleatum aggregation but decreased biofilm formation which were consistent with previous study concerning the effects of proanthoyanides on Staphylococcus epidermidis biofilm formation. Trentin et al. (2015) thought that the proposed mechanism of bacterial attachment inhibition was based on electrostatic repulsion and changes in hydrophilicity. This result is also in agreement with our observation from CLSM fluorescence imaging, which revealed that the biofilm changed from confluent and more evenly distributed to gather into distinct, easily discernible clusters after adding resveratrol.

Our data show that six selected genes were down-regulated after adding resveratrol in the biofilm formation. Among them, the $\mathrm{ABC}$ transporter substrate binding protein, which is encoded by FN0659, is a ubiquitous integral membrane protein that translocates from a variety of substrates, ranging from ions to macromolecules, either out of or into the cytosol (hence, they are defined as importers or exporters, respectively; Yu et al., 2015). It is also responsible for autoinducer 2 uptake into the cell which may play an important role in the $F$. nucleatum quorum sensing (QS) system (Rezzonico and Duffy, 2008). In previous research, a novel $\mathrm{ABC}$ transporter was identified in $R$. leguminosarum and required for biofilm formation. Seaton et al. (2011) predicted that SMu0836 and SMu0837 encoded $\mathrm{ABC}$ transporters and constructed a mutant strain $\triangle 836 \mathrm{p}$ in which a kanamycin resistance cassette replaced the SMu836 gene. They also found that the $\Delta 836 p$ strain had an impaired capacity to form biofilms (Vanderlinde et al., 2010; Seaton et al., 2011). The LysR family of transcriptional regulators encoded by FN0503 represents the most common type of transcriptional regulators in bacteria. Members of this family have a conserved structure with an N-terminal DNA-binding helix-turn-helix motif and a C-terminal co-inducer-binding domain. LysR-Type transcriptional regulators were among the most common types of positive regulators in prokaryotes. They have previously been shown to affect virulence, QS and biofilm formation. An $\operatorname{oxyR}$ (a LysR-Type Regulator)-defective mutant was constructed and impaired in biofilm formation in comparison to the parental strain (Bernier et al., 2008; Maddocks and Oyston, 2008; Hennequin and Forestier, 2009). Stress-induced proteins, such as DnaK (FN0116) and GroEL (FN0675) molecular chaperones, are considered to be heat shock proteins (Hsp) and participate in a variety of cellular processes including protein folding, protein trans-location, and the assembly/disassembly of protein complexes. These stressrelated genes are central for tolerance to environmental stresses and are important for QS. In previous studies, Lemos et al. (2007) created a knockdown strategy to lower the levels of DnaK by over $95 \%$ in strain SM12 and the level of GroEL about $80 \%$ in strain SM13. They found that, SM12 and SM13 had impaired biofilm-forming capacities compared with the wild-type strain (Yuan et al., 2005; Lemos et al., 2007). The key virulence factor, hemolysin (FN0132) caused lysis of erythrocytes, which provide iron and create an anaerobic environment by reducing the oxygen supply to the site of infection in Fusobacteria (Miao et al., 2010). Alizarin could inhibit S. aureus and S. epidermidis biofilm formation and repress expression of their hemolysin gene. Gowrishankar et al. (2012) found that two coral-associated bacterial (CAB) extracts reduced the production of EPS and hemolysin, which ultimately resulted in the significant inhibition of biofilms formed by both methicillin-resistant and -susceptible $S$. aureus (Lee et al., 2016). In addition, butyrate-acetoacetate CoA-transferase subunit B (FN1856) is suggested to be the most important route for the production of butyrate which is present in elevated levels in plaques associated with periodontitis, and may have the ability to penetrate the gingival epithelium (Bolstad et al., 1996; 
Hippe et al., 2011). These observations are consistent with our results that show that these genes were down-regulated in the presence of resveratrol. This may be the reason that biofilm formation was attenuated after adding resveratrol.

Evidence is accumulating showing that the ability to form biofilms in many organisms involves QS regulation. QS is a general cell-cell communication mechanism in the bacterial kingdom occurring via small diffusible signal molecules called autoinducers (AI), which act as members of a chemical "language" to coordinate bacterial population behaviors. Through the accumulation of bacterially produced AI, the bacterial population is able to sense increases in cell density and alter their gene expression accordingly to optimize their physiological response for a particular environmental stimulus and thereby modify the bacterial phenotype (Krysciak et al., 2011; Pei and Lamas-Samanamud, 2014). Therefore, we speculated that the natural compound resveratrol might attenuate $F$. nucleatum biofilm formation by disturbing its QS system, which was consistent with previous findings (Qin et al., 2014).

A wide variety of natural products have attracted considerable research interest because of their potential value in disease prevention and treatment. There is increasing demand from the public for natural products that can achieve desired antimicrobial and antiinflammatory effects for oral health care to complement and enhance the mechanical removal of plaque biofilms (Chen et al., 2011). Resveratrol, a natural compound found in some foods and drinks, inhibits the biofilm formation of some bacterial pathogens. Our study showed that resveratrol also inhibited F. nucleatum biofilm formation. However, Millhouse et al. (2014) have already found the resveratrol did not affect multi-species biofilm composition which seemed to be in disagreement with ours. The reason may be that the multi-species biofilm contains four bacteria including $S$. mitis, $F$. nucleatum, $P$. gingivalis, and $A$. actinomycetemcomitans. Among them, S. mitis was the most dominant species (83.24\%) in mature biofilm and the percentage of $F$. nucleatum was only $15.16 \%$. Since resveratrol can be used to treat or prevent $F$. nucleatum infection, its toxicity to mammalian cells needs to be clarified. Babich et al. (2000) found that the midpoint cytotoxicity values for a $24 \mathrm{~h}$ exposure to resveratrol were $400 \mu \mathrm{M}\left(\approx 100 \mu \mathrm{g} \mathrm{ml}^{-1}\right)$ for normal fibroblasts isolated from the oral cavity. The inhibition concentration used in our study was only 1.5625$25 \mu \mathrm{g} \mathrm{ml} \mathrm{ml}^{-1}$. Thus, resveratrol has little effect on normal human cells at this concentration. These data support that natural product resveratrol has developed non-aggressive and non-toxic therapeutic strategies to regulate biofilm formation. Therefore, resveratrol is considered to be a potential therapeutic

\section{REFERENCES}

Abdel-Nour, M., Duncan, C., Prashar, A., Rao, C., Ginevra, C., Jarraud, S., et al. (2014). The Legionella pneumophila collagen-like protein mediates sedimentation, autoaggregation, and pathogen-phagocyte interactions. Appl. Environ. Microbiol. 80, 1441-1454. doi: 10.1128/AEM.03254-13

Ali Mohammed, M. M., Nerland, A. H., Al-Haroni, M., and Bakken, V. (2013). Characterization of extracellular polymeric matrix, and treatment of target by attenuating the capacity of pathogenic bacteria to cause infection and unlikely to induce antimicrobial drug resistance.

\section{CONCLUSION}

Our study highlights that resveratrol has an inhibitory effect on F. nucleatum biofilm formation. The significant advantage of using resveratrol is that it does not affect the growth and survival of pathogenic bacteria at usable concentrations, thus avoiding selective pressure and the induction of resistance. Thus, resveratrol could be further explored as a means to prevent dental plague accumulation or F. nucleatum infection. However, natural biofilms as dental plaque are complex structures of multiple organisms which may behave quite differently from monoculture biofilms. Thus, further studies will contribute to understanding the molecular mechanism underlying the inhibitory effect of resveratrol on other oral bacteria biofilm formation, and possibly provide therapeutic or preventative methods for dental diseases.

\section{AUTHOR CONTRIBUTIONS}

JL: designed this study. ZHe: drafted paper and conducted the experiment. ZHu: revised the paper critically. WZ, ZT, and RM: do the acquisition, analysis, or interpretation of data. We declare that all listed authors have made substantial contributions. We also declare that nobody who qualifies for authorship has been excluded from the list of authors.

\section{FUNDING}

This work was supported by a grant from the National Natural Science Foundation of China [NSFC 81300866/81371143/81370024].

\section{SUPPLEMENTARY MATERIAL}

The Supplementary Material for this article can be found online at: http://journal.frontiersin.org/article/10.3389/fmicb. 2016.01065

FIGURE S1 | Gene expression of $\boldsymbol{F}$. nucleatum strain planktonic cultures. The results represent the means and SDs of three independent experiments performed in triplicate. No significant differences $(P>0.05)$ in gene expression between different concentrations.

Fusobacterium nucleatum and Porphyromonas gingivalis biofilms with DNase I and proteinase K. J. Oral Microbiol. 5. doi: 10.3402/jom.v5i0.20015

Augustine, N., Goel, A. K., Sivakumar, K. C., Kumar, R. A., and Thomas, S. (2014). Resveratrol-a potential inhibitor of biofilm formation in Vibrio cholerae. Phytomedicine 21, 286-289. doi: 10.1016/j.phymed.2013.09.010

Babich, H., Reisbaum, A. G., and Zuckerbraun, H. L. (2000). In vitro response of human gingival epithelial S-G cells to resveratrol. Toxicol. Lett. 114, 143-153. doi: 10.1016/S0378-4274(99)00288-X 
Bernier, S. P., Nguyen, D. T., and Sokol, P. A. (2008). A LysR-type transcriptional regulator in Burkholderia cenocepacia influences colony morphology and virulence. Infect. Immun. 76, 38-47. doi: 10.1128/iai.00874-07

Bolstad, A. I., Jensen, H. B., and Bakken, V. (1996). Taxonomy, biology, and periodontal aspects of Fusobacterium nucleatum. Clin. Microbiol. Rev. 9, 55-71.

Chen, Y., Wong, R. W., Seneviratne, C. J., Hagg, U., Mcgrath, C., Samaranayake, L. P., et al. (2011). The antimicrobial efficacy of Fructus mume extract on orthodontic bracket: a monospecies-biofilm model study in vitro. Arch. Oral Biol. 56, 16-21. doi: 10.1016/j.archoralbio.2010.08.006

Chusri, S., Sompetch, K., Mukdee, S., Jansrisewangwong, S., Srichai, T., Maneenoon, K., et al. (2012). Inhibition of Staphylococcus epidermidis biofilm formation by traditional thai herbal recipes used for wound treatment. Evid. Based Complement. Alternat. Med. 2012:159797. doi: 10.1155/2012/159797

Costerton, J. W., Stewart, P. S., and Greenberg, E. P. (1999). Bacterial biofilms: a common cause of persistent infections. Science 284, 1318-1322. doi: 10.1126/science.284.5418.1318

Das, T., Sharma, P. K., Busscher, H. J., Van Der Mei, H. C., and Krom, B. P. (2010). Role of extracellular DNA in initial bacterial adhesion and surface aggregation. Appl. Environ. Microbiol. 76, 3405-3408. doi: 10.1128/AEM.03119-09

de Lima Pimenta, A., Chiaradia-Delatorre, L. D., Mascarello, A., De Oliveira, K. A., Leal, P. C., Yunes, R. A., et al. (2013). Synthetic organic compounds with potential for bacterial biofilm inhibition, a path for the identification of compounds interfering with quorum sensing. Int. J. Antimicrob. Agents 42, 519-523. doi: 10.1016/j.ijantimicag.2013.07.006

Flemming, H. C., and Wingender, J. (2010). The biofilm matrix. Nat. Rev. Microbiol. 8, 623-633. doi: 10.1038 /nrmicro2415

Gowrishankar, S., Duncun Mosioma, N., and Karutha Pandian, S. (2012). Coralassociated bacteria as a promising antibiofilm agent against methicillin-resistant and -susceptible Staphylococcus aureus Biofilms. Evid Based Complement. Alternat. Med. 2012:862374. doi: 10.1155/2012/862374

Gursoy, U. K., Pollanen, M., Kononen, E., and Uitto, V. J. (2010). Biofilm formation enhances the oxygen tolerance and invasiveness of Fusobacterium nucleatum in an oral mucosa culture model. J. Periodontol. 81, 1084-1091. doi: 10.1902/jop.2010.090664

He, Z., Liang, J., Tang, Z., Ma, R., Peng, H., and Huang, Z. (2015). Role of the luxS gene in initial biofilm formation by Streptococcus mutans. J. Mol. Microbiol. Biotechnol. 25, 60-68. doi: 10.1159/000371816

He, Z., Wang, Q., Hu, Y., Liang, J., Jiang, Y., Ma, R., et al. (2012). Use of the quorum sensing inhibitor furanone C-30 to interfere with biofilm formation by Streptococcus mutans and its luxS mutant strain. Int. J. Antimicrob. Agents 40, 30-35. doi: 10.1016/j.ijantimicag.2012.03.016

Hennequin, C., and Forestier, C. (2009). oxyR, a LysR-type regulator involved in Klebsiella pneumoniae mucosal and abiotic colonization. Infect. Immun. 77, 5449-5457. doi: 10.1128/IAI.00837-09

Hippe, B., Zwielehner, J., Liszt, K., Lassl, C., Unger, F., and Haslberger, A. G. (2011). Quantification of butyryl CoA:acetate CoA-transferase genes reveals different butyrate production capacity in individuals according to diet and age. FEMS Microbiol. Lett. 316, 130-135. doi: 10.1111/j.1574-6968.2010. 02197.x

Jacqueline, C., and Caillon, J. (2014). Impact of bacterial biofilm on the treatment of prosthetic joint infections. J. Antimicrob. Chemother. 69(Suppl. 1), i37-i40. doi: $10.1093 / \mathrm{jac} / \mathrm{dku} 254$

Keskin, M., Kononen, E., Soderling, E., Isik, G., Firatli, E., Uitto, V. J., et al. (2014). Increased proliferation and decreased membrane permeability as defense mechanisms of Fusobacterium nucleatum against human neutrophilic peptide -1. Anaerobe 30, 35-40. doi: 10.1016/j.anaerobe.2014.08.001

Kolenbrander, P. E., Palmer, R. J. Jr., Rickard, A. H., Jakubovics, N. S., Chalmers, N. I., Diaz, P. I., et al. (2006). Bacterial interactions and successions during plaque development. Periodontology 2000, 47-79. doi: 10.1111/j.16000757.2006.00187.x

Krysciak, D., Schmeisser, C., Preuss, S., Riethausen, J., Quitschau, M., Grond, S., et al. (2011). Involvement of multiple loci in quorum quenching of autoinducer I molecules in the nitrogen-fixing symbiont Rhizobium (Sinorhizobium) sp. strain NGR234. Appl. Environ. Microbiol. 77, 5089-5099. doi: 10.1128/AEM.00112-11

Lee, H. R., Rhyu, I. C., Kim, H. D., Jun, H. K., Min, B. M., Lee, S. H., et al. (2011). In-vivo-induced antigenic determinants of Fusobacterium nucleatum subsp. nucleatum. Mol. Oral Microbiol. 26, 164-172. doi: 10.1111/j.20411014.2010.00594.x

Lee, H. S., Gu, F., Ching, S. M., Lam, Y., and Chua, K. L. (2010). CdpA is a Burkholderia pseudomallei cyclic di-GMP phosphodiesterase involved in autoaggregation, flagellum synthesis, motility, biofilm formation, cell invasion, and cytotoxicity. Infect. Immun. 78, 1832-1840. doi: 10.1128/IAI. 00446-09

Lee, J. H., Kim, Y. G., Ryu, S. Y., Cho, M. H., and Lee, J. (2014). Resveratrol oligomers inhibit biofilm formation of Escherichia coli O157:H7 and Pseudomonas aeruginosa. J. Nat. Prod. 77, 168-172. doi: 10.1021/np400756g

Lee, J. H., Kim, Y. G., Yong Ryu, S., and Lee, J. (2016). Calcium-chelating alizarin and other anthraquinones inhibit biofilm formation and the hemolytic activity of Staphylococcus aureus. Sci. Rep. 6:19267. doi: 10.1038/srep19267

Lee, K., Lee, J. H., Ryu, S. Y., Cho, M. H., and Lee, J. (2014). Stilbenes reduce Staphylococcus aureus hemolysis, biofilm formation, and virulence. Foodborne Pathog. Dis. 11, 710-717. doi: 10.1089/fpd.2014.1758

Lemos, J. A., Luzardo, Y., and Burne, R. A. (2007). Physiologic effects of forced down-regulation of $\mathrm{dnaK}$ and groEL expression in Streptococcus mutans. J. Bacteriol. 189, 1582-1588. doi: 10.1128/JB.01655-06

Maddocks, S. E., and Oyston, P. C. (2008). Structure and function of the LysR-type transcriptional regulator (LTTR) family proteins. Microbiology 154, 3609-3623. doi: 10.1099/mic.0.2008/022772-0

Miao, L., Liu, Y., Li, Q., Wang, Z., Li, H., and Zhang, G. (2010). Screening and sequence analysis of the hemolysin gene of Fusobacterium necrophorum. Anaerobe 16, 402-404. doi: 10.1016/j.anaerobe.2010.04.005

Millhouse, E., Jose, A., Sherry, L., Lappin, D. F., Patel, N., Middleton, A. M., et al. (2014). Development of an in vitro periodontal biofilm model for assessing antimicrobial and host modulatory effects of bioactive molecules. BMC Oral Health 14:80. doi: 10.1186/1472-6831-14-80

Molhoek, E. M., Van Dijk, A., Veldhuizen, E. J., Haagsman, H. P., and Bikker, F. J. (2011). A cathelicidin-2-derived peptide effectively impairs Staphylococcus epidermidis biofilms. Int. J. Antimicrob. Agents 37, 476-479. doi: 10.1016/j.ijantimicag.2010.12.020

Nyenje, M. E., Green, E., and Ndip, R. N. (2012). Biofilm formation and adherence characteristics of Listeria ivanovii strains isolated from ready-to-eat foods in Alice, South Africa. Sci. World J. 2012:873909. doi: 10.1100/2012/873909

Pei, R., and Lamas-Samanamud, G. R. (2014). Inhibition of biofilm formation by T7 bacteriophages producing quorum-quenching enzymes. Appl. Environ. Microbiol. 80, 5340-5348. doi: 10.1128/AEM.01434-14

Qin, N., Tan, X., Jiao, Y., Liu, L., Zhao, W., Yang, S., et al. (2014). RNA-Seqbased transcriptome analysis of methicillin-resistant Staphylococcus aureus biofilm inhibition by ursolic acid and resveratrol. Sci. Rep. 4:5467. doi: 10.1038/srep05467

Rezzonico, F., and Duffy, B. (2008). Lack of genomic evidence of AI-2 receptors suggests a non-quorum sensing role for luxS in most bacteria. BMC Microbiol. 8:154. doi: 10.1186/1471-2180-8-154

Sasaki-Imamura, T., Yano, A., and Yoshida, Y. (2010). Production of indole from L-tryptophan and effects of these compounds on biofilm formation by Fusobacterium nucleatum ATCC 25586. Appl. Environ. Microbiol. 76, 42604268. doi: 10.1128/AEM.00166-10

Seaton, K., Ahn, S. J., Sagstetter, A. M., and Burne, R. A. (2011). A transcriptional regulator and $\mathrm{ABC}$ transporters link stress tolerance, (p)ppGpp, and genetic competence in Streptococcus mutans. J. Bacteriol. 193, 862-874. doi: 10.1128/JB.01257-10

Sintim, H. O., and Gursoy, U. K. (2016). Biofilms as "connectors" for oral and systems medicine: a new opportunity for biomarkers, molecular targets, and bacterial eradication. OMICS 20, 3-11. doi: 10.1089/omi.2015.0146

Skar, C. K., Kruger, P. G., and Bakken, V. (2003). Characterisation and subcellular localisation of the GroEL-like and DnaK-like proteins isolated from Fusobacterium nucleatum ATCC 10953. Anaerobe 9, 305-312. doi: 10.1016/j.anaerobe.2003.08.004

Srinandan, C. S., Elango, M., Gnanadhas, D. P., and Chakravortty, D. (2015). Infiltration of matrix-non-producers weakens the salmonella biofilm and impairs its antimicrobial tolerance and pathogenicity. Front. Microbiol. 6:1468. doi: $10.3389 /$ fmicb.2015.01468

Tian, Y., He, X., Torralba, M., Yooseph, S., Nelson, K. E., Lux, R., et al. (2010). Using DGGE profiling to develop a novel culture medium suitable for oral 
microbial communities. Mol. Oral Microbiol. 25, 357-367. doi: 10.1111/j.20411014.2010.00585.x

Trappetti, C., Potter, A. J., Paton, A. W., Oggioni, M. R., and Paton, J. C. (2011). LuxS mediates iron-dependent biofilm formation, competence, and fratricide in Streptococcus pneumoniae. Infect. Immun. 79, 4550-4558. doi: 10.1128/IAI.05644-11

Trentin, D. S., Silva, D. B., Frasson, A. P., Rzhepishevska, O., Da Silva, M. V., Pulcini Ede, L., et al. (2015). Natural Green coating inhibits adhesion of clinically important bacteria. Sci. Rep. 5:8287. doi: 10.1038/srep08287

van den Bogaard, A. E., and Stobberingh, E. E. (2000). Epidemiology of resistance to antibiotics. Links between animals and humans. Int. J. Antimicrob. Agents 14, 327-335. doi: 10.1016/S0924-8579(00)00145-X

Vanderlinde, E. M., Harrison, J. J., Muszynski, A., Carlson, R. W., Turner, R. J., and Yost, C. K. (2010). Identification of a novel ABC transporter required for desiccation tolerance, and biofilm formation in Rhizobium leguminosarum bv. viciae 3841. FEMS Microbiol. Ecol. 71, 327-340. doi: 10.1111/j.15746941.2009.00824.x

Yu, J., Ge, J., Heuveling, J., Schneider, E., and Yang, M. (2015). Structural basis for substrate specificity of an amino acid ABC transporter. Proc. Natl. Acad. Sci. U.S.A. 112, 5243-5248. doi: 10.1073/pnas.1415037112
Yuan, L., Hillman, J. D., and Progulske-Fox, A. (2005). Microarray analysis of quorum-sensing-regulated genes in Porphyromonas gingivalis. Infect. Immun. 73, 4146-4154. doi: 10.1128/iai.73.7.4146-4154.2005

Zhang, P., Chomel, B. B., Schau, M. K., Goo, J. S., Droz, S., Kelminson, K. L., et al. (2004). A family of variably expressed outer-membrane proteins (Vomp) mediates adhesion and autoaggregation in Bartonella quintana. Proc. Natl. Acad. Sci. U.S.A. 101, 13630-13635. doi: 10.1073/pnas.04052 84101

Conflict of Interest Statement: The authors declare that the research was conducted in the absence of any commercial or financial relationships that could be construed as a potential conflict of interest.

Copyright (C) 2016 He, Huang, Zhou, Tang, Ma and Liang. This is an open-access article distributed under the terms of the Creative Commons Attribution License (CC BY). The use, distribution or reproduction in other forums is permitted, provided the original author(s) or licensor are credited and that the original publication in this journal is cited, in accordance with accepted academic practice. No use, distribution or reproduction is permitted which does not comply with these terms. 